\title{
Impacts of incorporating personal genome sequencing into graduate genomics education: a longitudinal study over three course years
}

Michael D. Linderman 1,2,5*, Saskia C. Sanderson 1,2,3,4, Ali Bashir 1,2, George A. Diaz , Andrew Kasarskis 1,2, Randi Zinberg ${ }^{2}$, Milind Mahajan ${ }^{1,2}$, Sabrina A. Suckiel ${ }^{1,2}$, Micol Zweig ${ }^{1,2}$ and Eric E. Schadt ${ }^{1,2}$

\begin{abstract}
Background: To address the need for more effective genomics training, beginning in 2012 the Icahn School of Medicine at Mount Sinai has offered a unique laboratory-style graduate genomics course, "Practical Analysis of Your Personal Genome" (PAPG), in which students optionally sequence and analyze their own whole genome. We hypothesized that incorporating personal genome sequencing (PGS) into the course pedagogy could improve educational outcomes by increasing student motivation and engagement. Here we extend our initial study of the pilot PAPG cohort with a report on student attitudes towards genome sequencing, decision-making, psychological wellbeing, genomics knowledge and pedagogical engagement across three course years.

Methods: Students enrolled in the 2013, 2014 and 2015 course years completed questionnaires before (T1) and after (T2) a prerequisite workshop ( $n=110)$ and before (T3) and after (T4) PAPG ( $n=66)$.

Results: Students' interest in PGS was high; 56 of 59 eligible students chose to sequence their own genome. Decisional conflict significantly decreased after the prerequisite workshop (T2 vs. T1 $p<0.001$ ). Most, but not all students, reported low levels of decision regret and test-related distress post-course (T4). Each year baseline decisional conflict decreased $(p<0.001)$ suggesting, that as the course became more established, students increasingly made their decision prior to enrolling in the prerequisite workshop. Students perceived that analyzing their own genome enhanced the genomics pedagogy, with students self-reporting being more persistent and engaged as a result of analyzing their own genome. More than $90 \%$ of respondents reported spending additional time outside of course assignments analyzing their genome.

Conclusions: Incorporating personal genome sequencing in graduate medical education may improve student motivation and engagement. However, more data will be needed to quantitatively evaluate whether incorporating PGS is more effective than other educational approaches.
\end{abstract}

Keywords: Genomics education, Personal genome sequencing, Whole genome sequencing

\footnotetext{
* Correspondence: mlinderman@middlebury.edu

${ }^{1}$ Icahn Institute for Genomics and Multiscale Biology, Icahn School of

Medicine at Mount Sinai, New York, NY, USA

${ }^{2}$ Department of Genetics and Genomic Sciences, Icahn School of Medicine at

Mount Sinai, New York, NY, USA

Full list of author information is available at the end of the article
} 


\section{Background}

Seeking to address the growing gap between the demand for genome sequencing and the supply of genomics professionals with the necessary training [1-10], in 2012 a multidisciplinary group of faculty at the Icahn School of Medicine at Mount Sinai developed, and have offered yearly since, a novel laboratory-style medical genomics course, "Practical Analysis of Your Personal Genome" (PAPG). The objective is to prepare future clinicians and researchers to effectively employ next generation sequencing (NGS) and, in particular, whole genome sequencing (WGS), around which we expect genomic medicine will ultimately converge. PAPG students uniquely have the opportunity, if they so choose, to sequence and analyze their own whole genome at no cost to them [11]. The motivating hypothesis was that for those students who desire to do so, the opportunity to analyze their own genome would improve educational outcomes by increasing their engagement with the course pedagogy and their motivation to master the complexity of genome analysis.

There are potential risks to accessing personal genome sequencing (PGS) results, particularly in an educational setting where distress could adversely impact the student's wellbeing and their learning [12-15]. The PAPG course sequence and sequencing protocol [11] were designed to promote informed decision-making, minimize the potential for test-related distress and maximize the educational value of incorporating PGS. To assess the protocol for and impacts of incorporating PGS into graduate genomics education, a companion research study has evaluated students' attitudes towards, decision-making for, and the outcomes of incorporating PGS into PAPG.

This manuscript expands upon previously reported results from the initial PAPG student cohort $(n=19)$ $[16,17]$. In 2012, students' baseline interest in sequencing their own genome was high, but many students expressed decisional conflict. Decisional conflict decreased after a prerequisite workshop, "Introduction to Human Genome Sequencing" (IHGS), that is part of the PAPG informed decision-making protocol, indicating that students perceived their decision as more informed after completing this pre-decision preparatory coursework [16]. Post-PAPG, most, but not all, of the 2012 students reported low levels of decision regret and testrelated distress [17]. In follow-up interviews, students reported that the opportunity to analyze their own genome positively contributed to their motivation and engagement [17].

The PAPG course has been offered yearly since 2012 and is now an established component of multiple training programs. Here we report on the attitudes towards genome sequencing, decision-making for PGS and psychological and educational outcomes of the 110 students enrolled in the 2013, 2014 and 2015 cohorts, comprising 59 students eligible to sequence their own genome, and a new comparison group of 51 primarily enrolled only in the prerequisite workshop. In these subsequent years we employed expanded questionnaires that incorporated a more relevant knowledge measure and new quantitative measures of engagement. This much larger cohort improves our understanding of the impacts of incorporating PGS into genomics pedagogy and represents one of the larger study cohorts to undergo predispositional WGS in any setting, not just education [18].

Our second aim was to evaluate changes between course years as the course, and WGS more generally, have become more established. Students in 2013-onwards had one or more years to anticipate enrolling in the course and contemplate the decision to sequence their own genome or not. And with the increasing use of genome sequencing in both research and clinical settings, students are increasingly likely to have encountered this technology prior to enrolling in the PAPG course sequence. We hypothesized that students' attitudes towards genome sequencing and their decision-making for PGS would be different by year as a result. This extended experience will inform how we evaluate courses of this kind and suggest trends that may also be observed among participants in predispositional PGS in non-educational settings.

\section{Methods}

\section{Study and course design}

This was a quantitative longitudinal cohort study in which an evolving set of anonymous questionnaires were administered to students enrolled in the "Practical Analysis of Your Personal Genome" (PAPG) course, and its prerequisite workshop "Introduction to Human Genome Sequencing" (IHGS), at the Icahn School of Medicine at Mount Sinai in the years 2013, 2014 and 2015. The study protocol, course design and approval process are described in more detail in related publications [11, $16,17]$. In brief, questionnaires were administered at 4 time points: before (T1) and immediately after (T2) IHGS, a two-day 15-h prerequisite workshop, and before (T3) and immediately after (T4) the semester-length PAPG course. The course sequence and study time line is summarized in Additional file 1: Figure S1. Paper questionnaires were administered in 2013 and transitioned to the online SurveyMonkey service for 2014 onwards.

As described in related publications, the Institutional Review Board at the Icahn School of Medicine at Mount Sinai determined the sequencing component of PAPG to not be research and this study (\#12-1273) to be exempt 
under category $2[11,16,17]$. Electronic consent was obtained from all participants at the beginning of each survey.

PAPG was a required course for students in the Masters of Science in Genetic Counseling program (MSGC) and offered as an elective course to other graduate students, medical students and clinical trainees. A maximum of 20 students per year enrolled in PAPG with the option to obtain and analyze their own whole genome sequence. We describe these students as "genome eligible". Starting in 2014, students could also enroll in PAPG without the option to obtain their own genome. All PAPG students were required to complete the prerequisite IHGS workshop. Additional seats in IHGS were opened to all students, faculty and employees of Mount Sinai Medical Center up to a maximum total enrollment of approximately 35 students per year. Thus approximately 15 students per year were not continuing onto PAPG and or not eligible to obtain their own genome sequence (these students knew that they would not be able to obtain their own genome sequence when they enrolled); these participants, described as "genome ineligible", serve as a comparison group for pre-test measures of interest, attitudes and psychological wellbeing. Enrollment and response rates are listed in Table 1; enrollment demographics are described in Additional file 1: Table S3.

As shown in the course timeline in Additional file 1: Figure S1 students make the decision to undergo whole genome sequencing after T2 (before T3) and obtain their genome sequence data (or a reference genome) after T3. Thus the T1 and T2 time points are "pre-decision", T3 is "post-decision" but "pre-results" and T4 is "post-results". This timeline differs from the previously reported 2012 cohort who made their decision after T3 [16]. PAPG students do not receive a report with a specific set of genetic findings; instead they receive the raw sequencing data and analyze it themselves in a structured way during the course. Thus the only results they "receive" are those they themselves generate. A student can choose to obtain their genome data but not actually view the data. As part of the course pedagogy PAPG students can create optional exclusion regions that mask variant calls in those genomic regions (described in more detail in [11]). The number of students reporting using exclusion regions, the time they reported spending analyzing their genomic data and the kinds and number of genomic findings they reported generating are described in the Results section.

\section{Measures}

The questionnaires assessed students' motivations for choosing to (not) sequence their own genome, decisionmaking, attitudes towards personal genome sequencing inside and outside the classroom, psychological wellbeing, actions, and self-rated and objectively measured genomics knowledge. Decision-related variables were assessed with the Decisional Conflict Scale (DCS) [19], the Decision Regret Scale (DRS) [20] and the Satisfaction with Decision Scale (SWD) [21]. Interests and attitudes were assessed with measures adapted from Ormond et al. [22] and measures developed for this study $[16,17]$. Depression was assessed with the 10question version of the Center for Epidemiologic Studies Depression Scale (CES-D 10) [23], anxiety with the short-form State-Trait Anxiety Inventory (STAI-6) [24] and test-related distress with an adapted version of the Multidimensional Impact of Cancer Risk Assessment (MICRA) [25]. Actions, such as use of exclusions, were assessed with questions developed specifically for this study. Self-rated knowledge was assessed with a measure adapted from the HealthSeq WGS study [26] and objective knowledge with a novel multiple choice test developed for this study. A complete listing of all measures, including any modifications to the published measure or scoring method, is included in the Supplemental Methods and Data [Additional file 1] along with copies of the survey instruments [Additional files 2, 3 and 4].

\section{Data analysis}

All data analysis was performed using the $\mathrm{R}$ statistical package version 3.2. Missing data was omitted. The Wilcoxon signed-rank test was used to compare differences

Table 1 Enrollment and survey response rate by year and time point. The numbers of PAPG students enrolled without the option to sequence their own genome are shown in parentheses

\begin{tabular}{|c|c|c|c|c|c|c|}
\hline & \multicolumn{2}{|l|}{2013} & \multicolumn{2}{|l|}{2014} & \multicolumn{2}{|l|}{2015} \\
\hline & IHGS Only & $\overline{I H G S}+\mathrm{PAPG}$ & IHGS Only & $\overline{I H G S}+$ PAPG & IHGS Only & IHGS + PAPG \\
\hline Enrolled & 19 & $19^{a}$ & 10 & $25(5)^{b}$ & 15 & $22(2)^{c}$ \\
\hline $\mathrm{T} 1$ & $15(79 \%)$ & 19 (100\%) & 10 (100\%) & $24(96 \%)$ & $10(66 \%)$ & 21 (95\%) \\
\hline $\mathrm{T} 2$ & $12(63 \%)$ & $16(84 \%)$ & $9(90 \%)$ & $23(92 \%)$ & $8(53 \%)$ & 19 (86\%) \\
\hline T3 & N/A & $17(89 \%)$ & N/A & $24(96 \%)$ & N/A & $18(82 \%)$ \\
\hline T4 & $\mathrm{N} / \mathrm{A}$ & 15 (79\%) & N/A & $21(84 \%)$ & N/A & 17 (77\%) \\
\hline
\end{tabular}

${ }^{\mathrm{a}}$ Two of these students dropped the course during the semester

${ }^{\mathrm{b}}$ Two of the students who enrolled without the option to obtain their genome dropped the course during the semester

'One of the students who enrolled without the option to obtain their genome dropped the course during the semester 
between pairs of time points for ordinal data. Kendall's tau was used to evaluate bivariate correlations. Repeated measures ANOVAs were performed with linear models. The Kruskal-Wallis or Wilcoxon-Mann-Whitney test (ordinal, for 3 and 2 years respectively) and Chi-square test (categorical) were used to evaluate differences between course years within a single time point. To account for multiple hypothesis testing, $p$-values $\leq 0.001$ were considered significant [27]. Effect sizes were computed using $r$ for ordinal data and $\phi$ for categorical data, and were described using Cohen's criteria of 0.1 for small effect, 0.3 for medium effect and 0.5 for large effect [28].

\section{Results}

\section{Student characteristics}

Table 1 summarizes enrollment and questionnaire response rates for 2013-2015. Students who enrolled in PAPG but were not eligible to sequence their own genome are shown in parentheses. Additional file 1: Table S3 summarizes enrollments by student program and background, e.g. MSGC or post-doctoral fellows.

\section{Interest, motivations and decision-making before and after prerequisite workshop}

Across the three course years 56 of 59 eligible students chose to sequence their own genome. Given the small number of students who chose a reference genome, we do not describe students' choices by year or demographics to maximize the confidentiality of their choice.

Figure 1 shows students' interest in sequencing their own genome and decisional conflict (DCS), before (T1) and after (T2) the prerequisite workshop by year and genome eligibility. Additional file 1: Table S4 summarizes the DCS subscales.

A significant decrease in decisional conflict in genome eligible students was observed after completion of the prerequisite workshop, with the mean score after the prerequisite workshop for all years (and overall) at or less than 25 , the threshold associated with implementing a decision [29]. For those students with a baseline DCS score $<25$ there is no significant change in DCS score after the prerequisite workshop $(\mathrm{Z}=-0.42, p=0.68, r=0.06, n=$ 26), while for those students with a baseline DCS score $\geq 25$, there was a large effect $(\mathrm{Z}=-4.11, p=2.3 \mathrm{e}-6$, $r=0.58, n=25)$. Only one of 27 students with a baseline DCS score $<25$ had a T2 DCS score $\geq 25$. Four students in total had DCS scores $\geq 37.5$ at T2, the threshold associated with feeling unsure about a decision [29].

Figure 1 suggests that there are differences in baseline DCS scores (i.e. at T1) between years and also in the change in DCS scores between T1 and T2. Performing a repeated measures ANOVA, we observed significant negative effects for the course $(\mathrm{F}(1,48)=16.6, p=0.00017)$, and

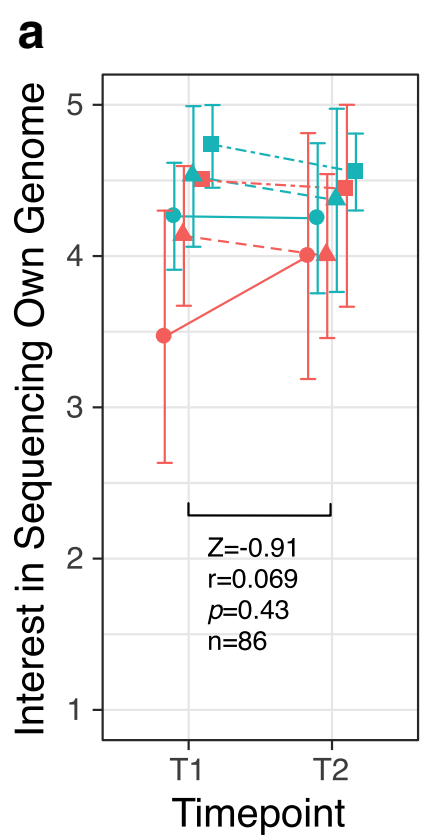

b

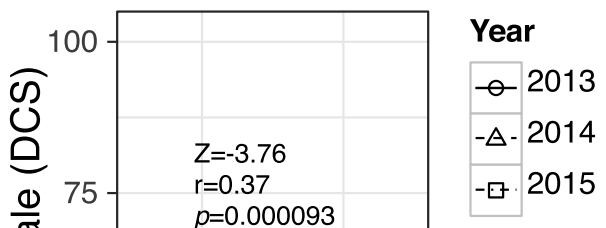

\section{Eligible to} Sequence Genome

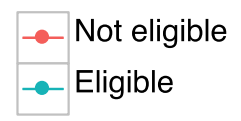

Fig. 1 Interest and decisional conflict before and after prerequisite course. Mean and 95\% confidence interval for: a interest in sequencing own genome, measured on a 1-5 scale from "No, definitely" to "Yes, definitely", and $\mathbf{b}$ decisional conflict (DCS) across time point, course year and eligibility to sequence own genome. Vertical axes show scale range. Wilcoxon-signed rank test between time points for all students is shown in each panel. DCS in panel $\mathbf{b}$ is annotated with cutoffs associated with implementing a decision $(<25)$ and feeling unsure about a decision $(>37.5)[29]$ 
course year $(\mathrm{F}(2,48)=9.18, p=0.00042)$, but not significant effects for the interaction $(\mathrm{F}(2,48)=2.08, p=0.14)$. These results suggest there is no significant difference in the impact of the prerequisite workshop on decisional conflict between course years.

To assess their motivations at $\mathrm{T} 1$ and $\mathrm{T} 2$, students were asked to indicate their agreement or disagreement with a set of statements about the potential benefits for and concerns about sequencing and analyzing their own genome. The results are summarized in Additional file 1: Table S5 for genome eligible students. At baseline the median student agreed that PAPG would be an opportunity to "get information that would help improve my health" and that their own genome would help them understand genetics concepts better. And the median student strongly agreed that PAPG would be an opportunity to "get a service that I would not ordinarily get if I had to pay full price". The median student also agreed that they were concerned that they "might get some results what would be disturbing", but disagreed or were neutral to the other proposed concerns.

While generally there was little significant change in students' concerns over the prerequisite workshop among genome eligible students, we did observe a significant decrease with medium effect size in agreement with "I feel that I would be at a disadvantage to my classmates if I did not undergo the testing" $(\mathrm{Z}=-3.35$, $p=0.00073, r=0.33, n=52$ ). After the introductory course, the median student disagreed with the statements "I would be concerned that my professors would know who took up the offer of testing and who did not" and "I would be concerned that my classmates would know who took up the offer of testing and who did not", with no students agreeing with the former.

\section{Satisfaction with decision and decision regret}

Figure 2 shows satisfaction with decision (SWD) before (T3) and after (T4) PAPG by year for genome eligible students. Mean (SD) scores on the Decision Regret Scale (DRS) after PAPG (T4) were 6.46 (10.1) with a range of $0-35$. Students were generally satisfied with their decision, with the mean SWD increasing after the PAPG course (mean SWD at T4 was greater than 4.5 in all years; the scale has a range of $1-5$ where 5 indicates high satisfaction). We did not observe a significant relationship between DCS at T2 and SWD $(\tau=-0.26$, $p=0.037, n=42)$ or DRS $(\tau=0.29, p=0.015, n=43)$.

\section{Impact of personal genome sequencing in PAPG} Analyses performed and genetic results obtained

Table 2 summarizes whether students who sequenced their own genome used that data for all or some analyses, what self-defined important results they generated in their analyses and with whom they discussed their

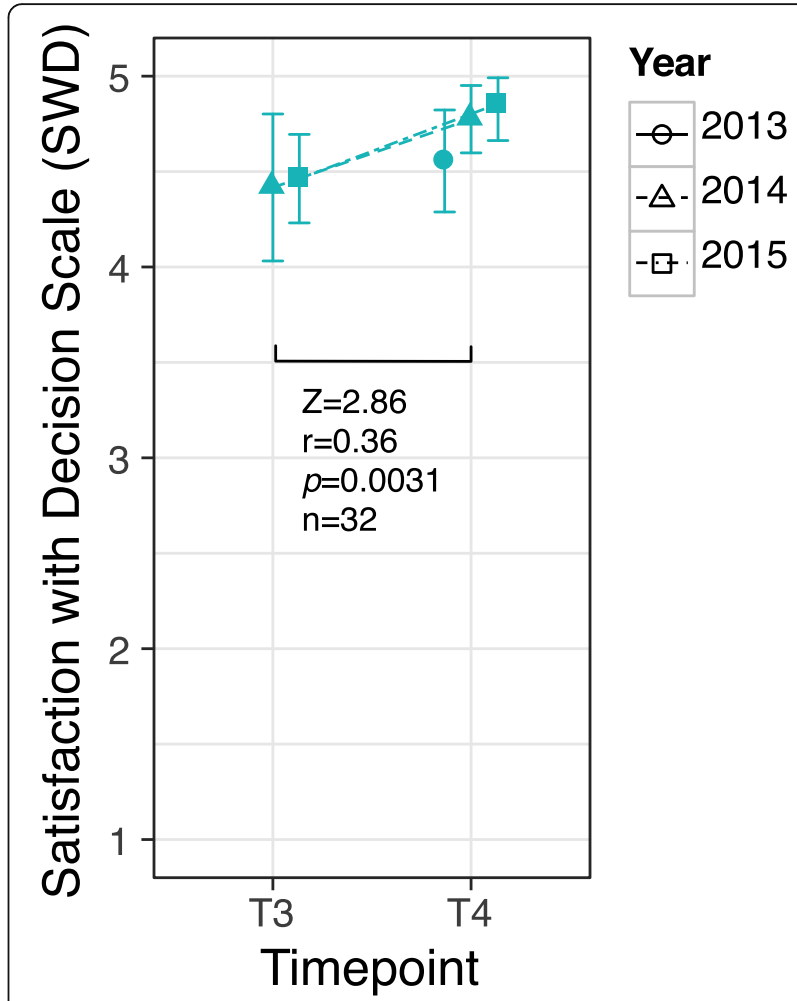

Fig. 2 Satisfaction with decision. Mean and 95\% confidence interval for satisfaction with decision (SWD) of genome eligible students before and after PAPG by course year. Wilcoxon-signed rank test between time points is shown

results. No significant differences were observed between years for these measures. All respondents used their genomic data for all analyses, with most respondents $(30,88.2 \%)$ reporting that they received results that were important to them. A small number of students $(4,11.8 \%)$ indicated that they incorporated exclusions into their analyses.

\section{Test-related distress and psychological wellbeing}

Figure 3a shows test-related distress (MICRA Distress subscale) after PAPG (T4) for students who chose to sequence their own genome. Mean (SD) MICRA Distress subscale across all years was 2.45 (3.59) and did not significantly differ between years $(\mathrm{H}(2)=3.35$, $p=0.19, n=43)$. There was not a significant relationship between DCS at T2 and test-related distress at T4 $(\mathrm{\tau}=0.15, p=0.21 n=42)$.

Figure $3 \mathrm{~b}$ and $\mathrm{c}$ shows measures of depression (CES-D 10 Dichotomous) and anxiety (STAI-6) across time points by course year for students who chose to sequence their own genome. For context, depression and anxiety measures at $\mathrm{T} 1$ and $\mathrm{T} 2$ for students who did not sequence their own genome are also shown. The majority of these students were enrolled only in the prerequisite course, and a minority were enrolled in PAPG but 
Table 2 Self-reported "important" genomic results identified by students who analyzed their own genome, and with whom students discussed their results for 2014-2015 at T4, post-course (questions were not included in 2013 T4 questionnaire)

\begin{tabular}{|c|c|}
\hline Use your genome for all analyses & T4 \\
\hline All & 34 \\
\hline Some & 0 \\
\hline Exclude regions & $\mathrm{T} 4^{\mathrm{a}}$ \\
\hline No & 30 \\
\hline Yes & 4 \\
\hline Receive any results felt were important & $\mathrm{T} 4^{\mathrm{b}}$ \\
\hline Yes & 30 \\
\hline No & 2 \\
\hline Not sure & 2 \\
\hline \multicolumn{2}{|l|}{ If yes, in which categories } \\
\hline Carrier status & $18(56 \%)$ \\
\hline Pharmacogenomic & $12(38 \%)$ \\
\hline Monogenic disease & $15(47 \%)$ \\
\hline Physical traits & $6(19 \%)$ \\
\hline Polygenic disease risk & $9(28 \%)$ \\
\hline Ancestry & $13(41 \%)$ \\
\hline Variant(s) of unknown significance & $10(31 \%)$ \\
\hline Other & 0 \\
\hline Discuss results with anyone & $\mathrm{T} 4^{\mathrm{C}}$ \\
\hline Yes & 29 \\
\hline No & 4 \\
\hline Choose not to answer & 1 \\
\hline \multicolumn{2}{|l|}{ If yes, whom (check all that apply) } \\
\hline Genetic counselor & $5(17 \%)$ \\
\hline Physician or other health professional & $4(14 \%)$ \\
\hline Mother & $18(62 \%)$ \\
\hline Father & $15(52 \%)$ \\
\hline Sibling & $12(41 \%)$ \\
\hline Other family & $6(21 \%)$ \\
\hline Friends & $24(83 \%)$ \\
\hline Significant other & $17(59 \%)$ \\
\hline Instructors & $10(34 \%)$ \\
\hline Other & 0 \\
\hline Course have impact on your family & $\mathrm{T} 4^{\mathrm{d}}$ \\
\hline Yes $^{\mathrm{e}}$ & 8 \\
\hline No & 24 \\
\hline Not sure & 2 \\
\hline
\end{tabular}

${ }^{a}$ Chi-square test of association with year was not significant: $x^{2}$ (1) $=0.016, p=0.90$

${ }^{b}$ Chi-square test of association with year was not significant: $x^{2}$ (2) $=1.89, p=0.39$

'Chi-square test of association with year was not significant: $x^{2}$ (2) $=0.92, p=0.63$

${ }^{\mathrm{d}}$ Chi-square test of association with year was not significant: $\mathrm{x}^{2}$ (2) $=2.56, p=0.28$

eFree text responses to how course impacted family listed in Additional file 1: Table S6 ineligible to sequence their own genome or were eligible but chose not to sequence their own genome. No significant changes were observed between $\mathrm{T} 3$ and $\mathrm{T} 4$ for either the depression $(\mathrm{Z}=0.90, p=0.37, r=0.094 n=46)$ or anxiety measures $(Z=0.26, p=0.80, r=0.027 n=47)$. There was not a significant relationship between DCS at $\mathrm{T} 2$ and depression at T4 $(\tau=-0.0026, p=0.98 n=43)$ or anxiety at T4 $(\tau=-0.064, p=0.56 n=42)$.

\section{Utility of PGS and perceived impact on student academic engagement}

Tables 3, 4 and 5 summarize students' perception of the utility of analyzing their own genome and the amount of analyses students performed outside of course assignments. Perception of utility was high at baseline and did not significantly change over the course timeline. Students who sequenced their own genome on average agreed with the proposed educational benefits of analyzing their own genome, particularly that they better understood the patient experience and that they performed greater number of and more thorough analyses. Almost all students reported analyzing additional variants outside of course assignments, including those students that did not analyze their own genome. For example, as shown in Table 5 outside of course assignments, the median student reported analyzing 6-10 additional variants and reported spending an additional $2-5 \mathrm{~h}$ analyzing their own genome.

\section{Impact of courses on genomics knowledge and application of learning}

Table 6 summarizes self-reported application of knowledge gained in class in their research, clinical or other professional activities as of the end of PAPG (T4). Most students (83\%) reported already applying what they learned in class.

Table 7 summarizes self-assessed and objectively measured knowledge over the course timeline. The entire course sequence (IHGS and PAPG) had a medium-tolarge positive effect on self-assessed understanding of WGS ( $\mathrm{Z}=3.22, p=0.0015, r=0.38, n=35)$ and a large and significant positive effect on objectively measured knowledge $(\mathrm{Z}=4.40, p=0.24 \mathrm{e}-7, r=0.57, n=30)$. Since almost all PAPG students have chosen to sequence their own genome, we cannot meaningfully compare changes between those who did and did not sequence their own genome. There was not a significant relationship between test-related distress reported at T4 and objective knowledge at T4 $(\tau=0.16, p=0.30, n=28)$ or the change in objective knowledge over PAPG $(\tau=-0.0040$, $p=0.98, n=26$ ) for students who chose to sequence their own genome. 


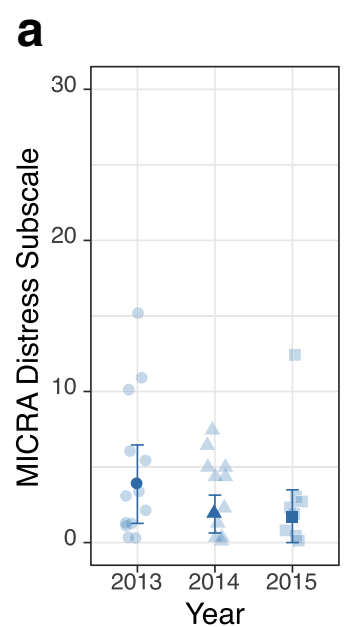

b

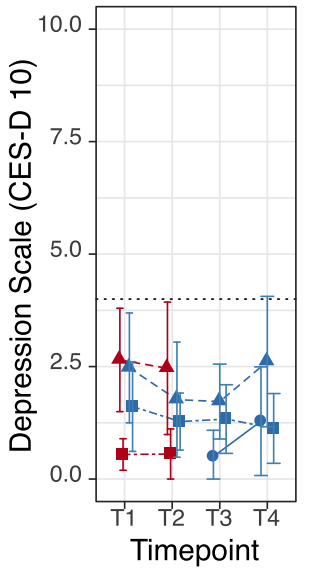

C

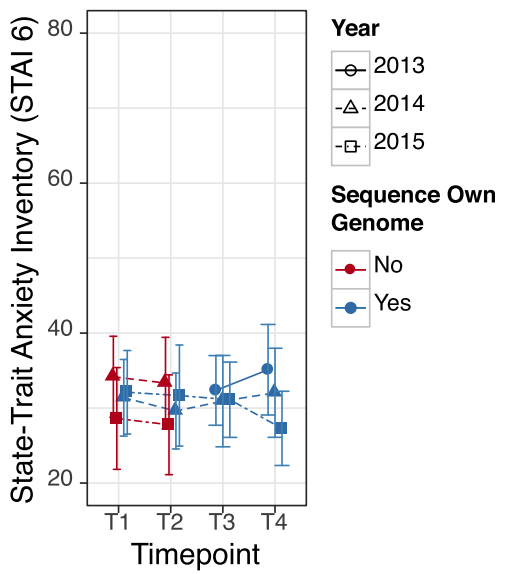

Fig. 3 Test-related distress and psychological wellbeing by time point and year. Mean and 95\% confidence interval for: a test-related distress (MICRA Distress subscale) post-course (T4), b depression (CES-D 10 Dichotomous), and c anxiety (STAI 6) across time point and course year. Individual scores on the MICRA Distress Subscale are shown in reduced opacity. For context, panels $\mathbf{b}$ and $\mathbf{c}$ also include reported depression and anxiety at T1 and T2 of students who did not sequence their own genome (either by choice or because they were ineligible). Since so few students at T3 and T4 could not or did not sequence their own genome, their data is not shown. The dotted line in panel $\mathbf{b}$ shows the cutoff for clinically significant depressive symptoms on the CES-D 10 Dichotomous ( $\geq 4$ ) [48]

\section{Impact of course sequence on attitudes toward genome sequencing}

In general students' responses to the attitudes statements did not change significantly over the course sequence (T4 vs. T1), with the exception of increased agreement with the statements "I know enough about genetics to understand the whole genome sequencing results" ( $\mathrm{Z}=3.53, p=3.4 \mathrm{e}-4, r=0.35, n=50)$ and "I understand the risks and benefits of using/getting personal whole genome sequencing done" $(\mathrm{Z}=3.88, p=6 \mathrm{e}-5$, $r=0.39, n=50)$, and increased disagreement with "Concerns about privacy/risks to privacy" is a reason to not use your own genome in class $(\mathrm{Z}=-3.66, p=1.6 \mathrm{e}-4$, $\mathrm{r}-0.44, n=34)$. Additional file 1: Tables S8-S10 summarize responses to the attitude measures. Responses to the above statements at T4 did not significantly differ between years: "I know enough..." $(\mathrm{H}(2)=5.52, p=0.063, n=52)$; "I understand the..." $(\mathrm{H}(2)=5.28, p=0.07, n=52)$; and "Concerns about privacy..." $(\mathrm{Z}=2.21, p=0.027, n=36)$.

\section{Discussion}

The results reported here from the 2013-2015 PAPG cohorts reinforce and extend our observations from the initial 2012 cohort [16, 17]: students' interest in sequencing their own genome was high, students felt their decision was more informed after the prerequisite workshop, and, at the completion of PAPG, most, but not all, students who sequenced their own genome reported low levels of decision regret and test-related distress. To the instructors and investigators knowledge, no 2013-2015 students experienced a focused episode of test-related distress like that reported by a 2012 student in response to a variant of unknown significance in a gene associated with adult-onset incompletely penetrant monogenic disease [17].

Although personal genomes play a large role in PAPG, homework and other course exercises are necessarily designed around instructor-provided genomic data so that there is a known correct answer and so that

Table 3 Mean (standard deviation) and range of Likert-scaled agreement with utility of analyzing your own genome (1-strongly disagree to 5-strongly agree)

\begin{tabular}{llllll}
\hline I think analyzing my own genome would be/was useful \\
\hline
\end{tabular}

${ }^{a}$ Wilcoxon-signed rank test between $\mathrm{T} 4$ and $\mathrm{T} 1$

${ }^{b} 45$ students not eligible to sequence own genome responded at $\mathrm{T} 1$, and 36 at $\mathrm{T} 2$ 
Table 4 Mean (standard deviation) and range of Likert-scaled agreement with engagement measures (1-strongly disagree to 5-strongly agree)

\begin{tabular}{ll}
\hline Because I used my genome $^{\mathrm{a}}$ & $\mathrm{T4}(n=34)^{\mathrm{b}}$ \\
\hline I was more persistent in completing & $4.24(1.02)$ \\
assignments or analyses & $1-5$ \\
I better understand the patient & $4.35(0.81)$ \\
experience & $2-5$ \\
I learned useful health or personal & $4.09(0.93)$ \\
information & $2-5$ \\
I better understand genetics concepts & $3.94(0.86)$ \\
& $2-5$ \\
I performed more analyses outside & $4.35(0.81)$ \\
of class & $2-5$ \\
I was more thorough in my analyses & $4.35(0.92)$ \\
& $2-5$
\end{tabular}

${ }^{a}$ Questions not in 2013 questionnaire

b Wilcoxon-Mann-Whitney test of association with year was not significant for any statement

students aren't required to "turn in" their own genomic data. Thus in many respects students have a typical pedagogical experience that includes the supervised, team-based, genomic analysis they will later perform professionally [30]. But they are then further exercising those new skills analyzing their own genomes (albeit more autonomously than would be the case in a clinical setting). Students reported also performing most or all of the same analyses on their own genomes, with a majority of students reporting spending $2-5$ or $5-10$ additional hours analyzing their genome outside of course exercises and assignments. And most, but not all, students agreed or strongly agreed that they were more persistent and performed more, and more thorough, analyses because they analyzed their own genomes. These quantitative data extends the pilot qualitative results from the 2012 PAPG cohort [17]. And these results are consistent with reports from other courses incorporating personal genomic testing (typically genotyping) in which students generally report that personal genomic testing enhanced their learning and improved their understanding of genomic testing and the patient experience [31-39].

We cannot, however, quantitatively determine whether incorporating PGS improves educational outcomes. Both self-assessed and objective measures of genomics knowledge increase after completing PAPG. However, since almost all students have elected to sequence their own genome, there is an insufficient comparison group to meaningfully evaluate the differences between students who did and did not sequence their own genome. And the context of PAPG did not allow the study to be implemented as a controlled randomized trial that could assess causality. Additional data will be needed to quantitatively assess the pedagogical value of PGS in PAPG.

The prerequisite workshop is intended to both educate and promote informed decision-making. As indicated by the significant decrease in decisional conflict, students feel that their decision was more informed after completing the prerequisite workshop. And afterwards fewer students were concerned that they would be at a disadvantage if they did not sequence their own genome and none of the respondents agreed that they were concerned that the faculty would know their choice. The educational setting creates additional potential for coercion; students could feel pressured to sequence their own genome, directly or indirectly, by the faculty or their peers. Ensuring that students do not feel disadvantaged in choosing a reference genome and do feel that their choice is private are both important to mitigating the possibility of coercion. These results indicate that the course design and sequencing protocol are achieving the above, and that the instructors are effectively communicating the protections that are in place.

We note students' decisional conflict is higher both at baseline and after the prerequisite workshop than that reported by participants in HealthSeq predispositional PGS study (mean of 11.34 before and 5.94 after genomic counseling) [40]. This difference

Table 5 The distribution of number of variants and the time students spent analyzing variants outside of course assignments

\begin{tabular}{|c|c|c|c|c|c|}
\hline $\begin{array}{l}\text { Variants analyzed } \\
\text { outside of } \\
\text { assignments }^{a}\end{array}$ & Own Genome ${ }^{b}$ & Ref. Genome & $\begin{array}{l}\text { Hours spent analyzing } \\
\text { genome outside of } \\
\text { assignments }^{\mathrm{a}}\end{array}$ & Own Genome & Ref. Genome \\
\hline 0 & 1 & 1 & Less than 1 & 3 & 2 \\
\hline $1-2$ & 3 & 0 & $1-2$ & 2 & 0 \\
\hline $3-5$ & 10 & 1 & $2-5$ & 14 & 1 \\
\hline $6-10$ & 11 & 1 & $5-10$ & 13 & 0 \\
\hline $11-20$ & 9 & 0 & $10-20$ & 4 & 0 \\
\hline $21-30$ & 3 & 0 & $20-30$ & 1 & 0 \\
\hline More than 30 & 1 & 0 & More than 30 & 0 & 0 \\
\hline
\end{tabular}

${ }^{a}$ Questions not in 2013 questionnaire

${ }^{\mathrm{b}}$ Linear-by-linear association with year was not significant: $Z=-0.49, p=0.63$

c Linear-by-linear association with year was not significant: $Z=-0.62, p=0.53$ 
Table 6 Application of knowledge gained in class from 2014 to 2015 reported at T4, post-course

\begin{tabular}{ll}
\hline Applied the knowledge gained in class & Students $^{a}$ \\
Yes & 31 \\
No & 5 \\
Not sure & 1 \\
If yes, in what ways? & 26 \\
Using online databases & 9 \\
Computing skills & 25 \\
Variant interpretation & 18 \\
Communicating NGS capabilities and limitations & 9 \\
Genome analysis pipeline & 3 \\
Other &
\end{tabular}

'Chi-square test of association with year was not significant: $X^{2}$

(2) $=0.83, p=0.66$

b "Other" responses listed in Additional file 1: Table S7

could reflect the many differences between these cohorts, including that the HealthSeq cohort is selfselected (individuals would likely not enroll in that study if they did not want genetic findings from WGS) whereas approximately half of PAPG students are required to enroll in the course, or that PAPG students are more knowledgeable about WGS than the general public. As more individuals obtain predispositional PGS [18] we will develop a better understanding of the correlates of informed decisionmaking; that data will inform development of muchneeded best practices for genomic counseling of ostensibly healthy individuals.
We observed student attitudes and outcomes to be similar between course years, except at baseline. Baseline interest increased and decisional conflict decreased each year, that is students increasingly began the course with more certainty in their decision to sequence their own genome or not. Over the study period the course became more established and students had one or more years to anticipate enrollment and the decision to sequence their own genome. Concurrently genome sequencing became more widely used in both clinical and research settings and thus students are more likely to have already encountered this technology at baseline. Thus we hypothesize that over time more of the decision-making process takes place prior to enrolling in the PAPG course sequence. And indeed we observed that in 2014 and 2015 baseline mean decisional conflict was below the threshold associated with implementing a decision, and baseline average agreement with both "I know enough about genetics to understand the WGS results" and particularly "I understand the risks and benefits of using/getting personal WGS done" increased each year. These results suggest that courses like PAPG, and perhaps predispositional PGS more generally, may need to be evaluated over several years to determine "steady-state" measures of decision-making.

Limitations for this study include: the single site; a larger but still small sample size with missing responses; and the possibility for students under- or over-reporting variables that may be critical or supportive of the course design, respectively, out of concern for impacts on the institution, instructors and the continued availability of

Table 7 Mean (standard deviation) and range of self- and objectively-assessed genetics and genomics knowledge across all students and time points

\begin{tabular}{|c|c|c|c|c|c|}
\hline Self-assessed knowledge & $\mathrm{T} 1(n=65)$ & $\mathrm{T} 2(n=57)$ & T3 $(n=52)$ & T4 $(n=52)$ & Test $(n=35)^{\mathrm{a}}$ \\
\hline Confidence & $\begin{array}{l}2.9(1.1) \\
1-5\end{array}$ & $\begin{array}{l}3.4(0.9) \\
1-5\end{array}$ & $\begin{array}{l}3.1(1.0 \\
1-5\end{array}$ & $\begin{array}{l}3.6(0.7)^{b} \\
1-5\end{array}$ & $\begin{array}{l}Z=2.82, r=0.37 \\
p=0.0041\end{array}$ \\
\hline Current understanding of genetics & $\begin{array}{l}4.17(0.78) \\
2-5\end{array}$ & $\begin{array}{l}4.09(0.71) \\
2-5\end{array}$ & $\begin{array}{l}4.31(0.64) \\
3-5\end{array}$ & $\begin{array}{l}4.19(0.69) \\
3-5\end{array}$ & $\begin{array}{l}Z=-0.30, r=0.04 \\
p=0.99\end{array}$ \\
\hline Genetics knowledge compared to others & $\begin{array}{l}4.11(0.89) \\
2-5\end{array}$ & $\begin{array}{l}4.05(0.66) \\
2-5\end{array}$ & $\begin{array}{l}4.19(0.66) \\
2-5\end{array}$ & $\begin{array}{l}4.46(0.58) \\
3-5\end{array}$ & $\begin{array}{l}Z=2.01 r=0.24 \\
p=0.065\end{array}$ \\
\hline Current understanding of WGS & $\begin{array}{l}3.68(0.87) \\
2-5\end{array}$ & $\begin{array}{l}3.88(0.71) \\
2-5\end{array}$ & $\begin{array}{l}3.75(0.74) \\
2-5\end{array}$ & $\begin{array}{l}4.08(0.65) \\
3-5\end{array}$ & $\begin{array}{l}Z=3.22, r=0.38 \\
p=0.0015\end{array}$ \\
\hline Current WGS knowledge compared to others & $\begin{array}{l}3.86(0.83) \\
2-5\end{array}$ & $\begin{array}{l}3.95(0.85) \\
2-5\end{array}$ & $\begin{array}{l}3.92(0.79) \\
2-5\end{array}$ & $\begin{array}{l}4.42(0.54) \\
3-5\end{array}$ & $\begin{array}{l}Z=3.13, r=0.37 \\
p=0.0026\end{array}$ \\
\hline Objective knowledge & $\mathrm{T} 1(n=60)$ & $\mathrm{T} 2(n=53)$ & $\mathrm{T} 3(n=37)$ & $\mathrm{T} 4(n=33)$ & Test $(n=30)^{a}$ \\
\hline Genomics test & $\begin{array}{l}2.5(1.7)^{c} \\
0-7\end{array}$ & $\begin{array}{l}3.1(1.5) \\
0-7\end{array}$ & $\begin{array}{l}2.9(1.7) \\
0-7\end{array}$ & $\begin{array}{l}4.3(1.8)^{\mathbf{d}} \\
1-9\end{array}$ & $\begin{array}{l}Z=4.40, r=0.57 \\
p=9.24 \mathrm{e}-7\end{array}$ \\
\hline
\end{tabular}

Confidence is reported on a 1-5 scale from "No confidence" to "High confidence". Current understanding is reported on a 1-5 scale from "None" to "High", while knowledge compared is reported on a 1-5 scale from "Much less than others" to "Much more than others". Test results are reported for paired comparison of T1 and T4. Total number of valid responses shown at each time point. The objective knowledge measure, range 0-10, was only included in 2014-2015

${ }^{a}$ Wilcoxon-signed rank test between $\mathrm{T} 4$ and $\mathrm{T} 1$, and thus only including eligible students

${ }^{\mathrm{b}}$ Only 44 participants answered this question at T4

'Wilcoxon-Mann-Whitney test of association with year was not significant: $Z=-1.11, p=0.27$

${ }^{d}$ Wilcoxon-Mann-Whitney test of association with year was not significant: $Z=-1.27, p=0.21$ 
the course. The online questionnaires incorporated themes from follow-up qualitative interviews with initial 2012 cohort [17], but necessarily would not have captured all attitudes or outcomes that may have been elicited in an interview. With a predicted rate of healthrelevant adult-onset monogenic disease variants on the order of $1-5 \%$ [41-43], this study is not yet well powered to detect distress, and impacts thereof, caused by these rare variants. And since all impacts are selfreported, students may have experienced test-related distress but not reported it on the questionnaires or to the course or study team. Where possible we utilized validated and widely used measures that permit comparison to other cohorts and contexts. At present, however, there is no common, rigorously validated, measure of genomics knowledge making it difficult to compare PAPG to other educational approaches [44]. Developing such a measure is a key area of future work. PAPG is a required course for approximately half of the students, cohorts that are entirely self-selected (or entirely required) may respond differently to PGS in an educational setting.

\section{Conclusions}

PAPG is one of several experiments in participatory genomics pedagogy [44] that also include incorporating personal genotyping [31-39, 45], analyzing cadaver genomes in anatomy lab [46], and bench-top sequencing [47]. At present, the cost and complexity of WGS are barriers to implementing educational PGS more widely. However, in the future we expect WGS to be widely available at low cost; thus the question of whether to incorporate PGS into genomics education will be strictly of the balance between the educational benefits and the possible adverse effects [11]. Here we showed that: the prerequisite workshop and associated materials promoted more informed decision-making about PGS; most, but not all students, reported low levels of decision regret and test-related distress; and students reported being more engaged and persistent as a result of sequencing and analyzing their own genome as part of the course. We hope this report about our multi-year experience incorporating PGS into graduate-level genomics education will contribute to the important ongoing discussion on how to most effectively train the much-needed next-generation of genomics professionals.

\section{Additional files}

\section{Additional file 1: Supplemental methods and data referenced in text.} (PDF $183 \mathrm{~kb}$ )

Additional file 2: Questionnaire administered at time points $\mathrm{T} 1$ and $\mathrm{T} 2$. (PDF $680 \mathrm{~kb}$ )

Additional file 3: Questionnaire administered at time point T3. (PDF $725 \mathrm{~kb}$ )
Additional file 4: Questionnaire administered at time point T4. (PDF $791 \mathrm{~kb}$ )

Abbreviations

PGS: Personal genome sequencing; WGS: Whole genome sequencing

\section{Acknowledgements}

This work was supported in part through the computational resources and staff expertise provided by Scientific Computing at the Icahn School of Medicine at Mount Sinai, and the BERD statistical consultation service sponsored by Conduits through the National Center for Research Resources and the National Center for Advancing Translational Sciences of the National Institutes of Health under Award Number UL1TR001433. The authors gratefully acknowledge the assistance of Weiva Sieh.

\section{Funding}

Research reported in this publication was supported in part by the National Human Genome Research Institute of the National Institutes of Health under Award Number R03HG008809.

\section{Availability of data and materials}

The datasets used and/or analyzed during the current study are available from the corresponding author on reasonable request.

\section{Authors' contributions}

MDL performed the analyses and drafted the manuscript, co-developed and directed the courses, and contributed to the conception and design of the study. SCS contributed to the conception and design of the study, designed the questionnaires, and co-developed the courses. AB, GAD, AK, RZ and MM contributed to the conception and design of the study and co-developed the courses. SAS and MZ contributed to data acquisition and questionnaire design. EES contributed to the conception, design and coordination of the study. All authors read and approved the final manuscript.

\section{Ethics approval and consent to participate}

The Institutional Review Board at the Icahn School of Medicine at Mount Sinai determined this study (\#12-1273) to be exempt.

\section{Consent for publication}

N/A

\section{Competing interests}

The authors declare that they have no competing interests.

\section{Publisher's Note}

Springer Nature remains neutral with regard to jurisdictional claims in published maps and institutional affiliations.

\section{Author details}

${ }^{1}$ Icahn Institute for Genomics and Multiscale Biology, Icahn School of Medicine at Mount Sinai, New York, NY, USA. ${ }^{2}$ Department of Genetics and Genomic Sciences, Icahn School of Medicine at Mount Sinai, New York, NY, USA. ${ }^{3}$ Health Behaviour Research Centre, Department of Epidemiology and Public Health, University College London, London, UK. ${ }^{4}$ Department of

Clinical Genetics, Great Ormond Street Hospital, London, UK. ${ }^{5}$ Department of Computer Science, Middlebury College, Middlebury, VT, USA.

Received: 4 April 2017 Accepted: 2 January 2018

Published online: 30 January 2018

\section{References}

1. Guttmacher AE, Porteous ME, JD MI. Educating health-care professionals about genetics and genomics. Nat Rev Genet. 2007;8:151-7. Available from: http://www.ncbi.nlm.nih.gov/pubmed/17230201. Cited 16 Jan 2015

2. Salari K. The dawning era of personalized medicine exposes a gap in medical education. PLoS Med. 2009;6:e1000138. Available from: http:// www.pubmedcentral.nih.gov/articlerender.fcgi?artid=2719811\&tool= pmcentrez\&rendertype=abstract. Cited 16 Jan 2015

3. Haspel RL, Arnaout R, Briere L, Kantarci S, Marchand K, Tonellato P, et al. A call to action: training pathology residents in genomics and personalized 
medicine. Am J Clin Pathol. 2010;133:832-4. Available from: http://www. ncbi.nlm.nih.gov/pubmed/20472839. Cited 24 Dec 2013

4. Patay BA, Topol EJ. The unmet need of education in genomic medicine. Am J Med. 2012;125:5-6. Available from: http://www.ncbi.nlm.nih.gov/pubmed/ 22195527. Cited 24 Dec 2013

5. Hooker GW, Ormond KE, Sweet K, Biesecker BB. Teaching genomic counseling: preparing the genetic counseling workforce for the genomic era. J Genet Couns. 2014;23:445-51. Available from: http://www.ncbi.nlm.nih. gov/pubmed/24504939. Cited 1 Aug 2014

6. Korf BR, Berry AB, Limson M, Marian AJ, Murray MF, O'Rourke PP, et al. Framework for development of physician competencies in genomic medicine: report of the Competencies Working Group of the Inter-Society Coordinating Committee for Physician Education in Genomics. Genet Med. 2014;16:804-9. Available from: http://www.nature.com/gim/journal/v16/n11/ full/gim201435a.html. Cited 12 Nov 2014

7. Vassy JL, Korf BR, Green RC. How to know when physicians are ready for genomic medicine. Sci Transl Med. 2015;7:287fs19. Available from: http:// stm.sciencemag.org/content/7/287/287fs19.short. Cited 15 May 2015

8. Christensen KD, Vassy JL, Jamal L, Lehmann LS, Slashinski MJ, Perry DL, et al. Are physicians prepared for whole genome sequencing? A qualitative analysis. Clin Genet. 2015; Available from: http://www.ncbi.nlm.nih.gov/ pubmed/26080898. Cited 18 June 2015

9. Feero WG, Manolio TA, Khoury MJ. Translational research is a key to nongeneticist physicians' genomics education. Genet Med. 2014;16:871-3. Available from: http://dx.doi.org/10.1038/gim.2014.67. Cited 26 Jan 2015

10. Feero WG, Green ED. Genomics education for health care professionals in the 21st century. JAMA. 2011;306:989-90. Available from: http://jama. jamanetwork.com/article.aspx?articleid=1104276. Cited 6 Oct 2014

11. Linderman MD, Bashir A, Diaz GA, Kasarskis A, Sanderson SC, Zinberg RE, et al. Preparing the next generation of genomicists: a laboratory-style course in medical genomics. BMC Med Genet. 2015;8:47. Available from: http://www.pubmedcentral.nih.gov/articlerender.fcgi?artid=4534145\&tool= pmcentrez\&rendertype=abstract. Cited 17 Aug 2015

12. Callier SL. Swabbing students: should universities be allowed to facilitate educational DNA testing? Am J Bioeth. 2012;12:32-40. Available from: http://www.pubmedcentral.nih.gov/articlerender.fcgi?artid=3390747\&tool= pmcentrez\&rendertype=abstract. Cited 24 Dec 2013

13. Salari K, Pizzo PA, Prober CG. Commentary: to genotype or not to genotype? Addressing the debate through the development of a genomics and personalized medicine curriculum. Acad Med. 2011;86: 925-7. Available from: http://www.ncbi.nlm.nih.gov/pubmed/21795901. Cited 24 Dec 2013

14. Parker LS, Grubs R. Ethical considerations regarding classroom use of personal genomic information. J Microbiol Biol Educ. 2014;15:191-6. Available from: http://www.pubmedcentral.nih.gov/articlerender.fcgi?artid= 4278476\&tool=pmcentrez\&rendertype=abstract. Cited 24 Apr 2016

15. Walt DR, Kuhlik A, Epstein SK, Demmer LA, Knight M, Chelmow D, et al. Lessons learned from the introduction of personalized genotyping into a medical school curriculum. Genet Med. 2011;13:63-6. Available from: http:// www.ncbi.nlm.nih.gov/pubmed/21057320. Cited 24 Dec 2013

16. Sanderson SC, Linderman MD, Kasarskis A, Bashir A, Diaz GA, Mahajan M, et al. Informed decision-making among students analyzing their personal genomes on a whole genome sequencing course: a longitudinal cohort study. Genome Med. 2013;5:113. Available from: http://www.ncbi.nlm.nih. gov/pubmed/24373383. Cited 9 Jan 2014

17. Sanderson SC, Linderman MD, Zinberg R, Bashir A, Kasarskis A, Zweig M, et al. How do students react to analyzing their own genomes in a wholegenome sequencing course?: outcomes of a longitudinal cohort study. Genet Med. 2015;17:866-74. Available from: http://www.ncbi.nlm.nih.gov/ pubmed/25634025. Cited 30 Jan 2015

18. Linderman MD, Nielsen DE, Green RC. Personal genome sequencing in ostensibly healthy individuals and the PeopleSeq consortium. J Pers Med. 2016;6:14. Available from: http://www.ncbi.nlm.nih.gov/pubmed/ 27023617

19. O'Connor AM. Validation of a decisional conflict scale. Med Decis Mak. 15: 25-30. Available from: http://www.ncbi.nlm.nih.gov/pubmed/7898294. Cited 30 Mar 2016

20. Brehaut JC, O'Connor AM, Wood TJ, Hack TF, Siminoff L, Gordon E, et al. Validation of a decision regret scale. Med Decis Mak. 23:281-92. Available from: http://www.ncbi.nlm.nih.gov/pubmed/12926578. Cited 22 Apr 2016
21. Holmes-Rovner M, Kroll J, Schmitt N, Rovner DR, Breer ML, Rothert ML, et al. Patient satisfaction with health care decisions: the satisfaction with decision scale. Med Decis Mak. 16:58-64. Available from: http://www.ncbi.nlm.nih. gov/pubmed/8717600. Cited 22 Apr 2016

22. Ormond KE, Hudgins L, Ladd JM, Magnus DM, Greely HT, Cho MK. Medical and graduate students' attitudes toward personal genomics. Genet Med. 2011;13:400-8. Available from: http://www.ncbi.nlm.nih.gov/pubmed/ 21270640. Cited 8 Mar 2013

23. Kohout FJ, Berkman LF, Evans DA, Cornoni-Huntley J. Two shorter forms of the CES-D (Center for Epidemiological Studies Depression) depression symptoms index. J Aging Health. 1993;5:179-93. Available from: http://www. ncbi.nlm.nih.gov/pubmed/10125443. Cited 22 Apr 2016

24. Marteau TM, Bekker H. The development of a six-item short-form of the state scale of the Spielberger State-Trait Anxiety Inventory (STAI). Br J Clin Psychol. 1992;31(Pt 3):301-6. Available from: http://www.ncbi.nlm.nih.gov/ pubmed/1393159. Cited 31 Dec 2015

25. Cella D, Hughes C, Peterman A, Chang C-H, Peshkin BN, Schwartz MD, et al. A brief assessment of concerns associated with genetic testing for cancer: the Multidimensional Impact of Cancer Risk Assessment (MICRA) questionnaire. Health Psychol. 2002;21:564-72. Available from: http://www. ncbi.nlm.nih.gov/pubmed/12433008. Cited 22 Apr 2016

26. Sanderson SC, Linderman MD, Suckiel SA, Diaz GA, Zinberg RE, Ferryman K, et al. Motivations, concerns and preferences of personal genome sequencing research participants: baseline findings from the HealthSeq project. Eur J Hum Genet. 2016;24:14-20. Available from: http://dx.doi.org/ 10.1038/ejhg.2015.118. Cited 3 June 2015

27. Colquhoun D. An investigation of the false discovery rate and the misinterpretation of p-values. R Soc Open Sci. 2014;1:140216. Available from: http://www.pubmedcentral.nih.gov/articlerender.fcgi?artid=4448847\&tool= pmcentrez\&rendertype=abstract. Cited 20 Nov 2014

28. Cohen J. Statistical power analysis for the behavioral sciences: L. Erlbaum Associates; 1988. Available from: http://worldcat.org/oclc/17877467. Cited 15 Apr 2016

29. O'Connor A. User manual - decisional conflict scale (16 item statement format). Ottawa; 1993. Available from: https://decisionaid.ohri.ca/docs/ develop/User_Manuals/UM_Decisional_Conflict.pdf. Accessed 15 Apr 2016

30. Korf BR. Pushing the envelope in genomics education. Genet Med. 2015; Available from: http://www.ncbi.nlm.nih.gov/pubmed/25790159. Cited 23 Mar 2015

31. Krynetskiy E, Lee Calligaro I. Introducing pharmacy students to pharmacogenomic analysis. Am J Pharm Educ. 2009;73:71. Available from: http://www.pubmedcentral.nih.gov/articlerender.fcgi?artid=2720367\&tool= pmcentrez\&rendertype=abstract. Cited 24 Dec 2013

32. Sharp RR, Goldlust ME, Eng C. Addressing gaps in physician education using personal genomic testing. Genet Med. 2011;13:750-1. Available from: http:// www.ncbi.nlm.nih.gov/pubmed/21814069. Cited 16 Jan 2015

33. Vernez SL, Salari K, Ormond KE, Lee SS-J. Personal genome testing in medical education: student experiences with genotyping in the classroom. Genome Med. 2013;5:24. Available from: http://www.pubmedcentral.nih. gov/articlerender.fcgi?artid=3706781\&tool=pmcentrez\&rendertype $=$ abstract. Cited 24 Dec 2013

34. Salari K, Karczewski KJ, Hudgins L, Ormond KE. Evidence that personal genome testing enhances student learning in a course on genomics and personalized medicine. PLoS One. 2013;8:e68853. Available from: http:// www.pubmedcentral.nih.gov/articlerender.fcgi?artid=3720862\&tool= pmcentrez\&rendertype=abstract. Cited 24 Dec 2013

35. O'Brien TJ, LeLacheur S, Ward C, Lee NH, Callier S, Harralson AF. Impact of a personal CYP2D6 testing workshop on physician assistant student attitudes toward pharmacogenetics. Pharmacogenomics. 2016; Available from: http://www.futuremedicine.com/doi/full/10.2217/pgs.15.182. Cited 25 Feb 2016

36. Weitzel KW, McDonough CW, Elsey AR, Burkley B, Cavallari LH, Johnson JA. Effects of using personal genotype data on student learning and attitudes in a pharmacogenomics course. Am J Pharm Educ. 2016;80: 122. Available from: http://www.ncbi.nlm.nih.gov/pubmed/27756930. Cited 18 Nov 2016

37. Adams SM, Anderson KB, Coons JC, Smith RB, Meyer SM, Parker LS, et al. Advancing pharmacogenomics education in the core pharmd curriculum through student personal genomic testing. Am J Pharm Educ. 2016;80:3. Available from: http://www.ncbi.nlm.nih.gov/pubmed/26941429. Cited 22 Nov 2016 
38. Frick A, Benton CS, Scolaro KL, McLaughlin JE, Bradley CL, Suzuki OT, et al. Transitioning pharmacogenomics into the clinical setting: training future pharmacists. Front Pharmacol. 2016;7 Available from: http://journal. frontiersin.org/Article/10.3389/fphar.2016.00241/abstract. Cited 5 Oct 2017

39. Surofchy D, Oh S, Galanter J, Xiang P, Li M, Guo S, et al. The effects of personal pharmacogenetic testing on the effects of pharmacy student perceptions of knowledge and attitudes towards precision medicine. Inov Pharm. 2017;8 Available from: http://pubs.lib.umn.edu/innovations/vol8/iss1/ 2. Cited 28 Jan 2017

40. Suckiel SA, Linderman MD, Sanderson SC, Diaz GA, Wasserstein M, Kasarskis $A$, et al. Impact of genomic counseling on informed decision-making among ostensibly healthy individuals seeking personal genome sequencing the HealthSeq project. J Genet Couns. 2016;25:1044-53. Available from: http://www.ncbi.nlm.nih.gov/pubmed/26898680

41. Dorschner MO, Amendola LM, Turner EH, Robertson PD, Shirts BH, Gallego $\mathrm{CJ}$, et al. Actionable, pathogenic incidental findings in 1,000 participants' exomes. Am J Hum Genet. 2013;93:631-40. Available from: http://www. sciencedirect.com/science/article/pii/S0002929713003819. Cited 17 Jan 2014

42. Gambin T, Jhangiani SN, Below JE, Campbell IM, Wiszniewski W, Muzny $\mathrm{DM}$, et al. Secondary findings and carrier test frequencies in a large multiethnic sample. Genome Med. 2015;7:54. Available from: http:// www.pubmedcentral.nih.gov/articlerender.fcgi?artid=4507324\&tool= pmcentrez\&rendertype=abstract. Cited 16 June 2015

43. Johnston JJ, Lewis KL, Ng D, Singh LN, Wynter J, Brewer C, et al. Individualized iterative phenotyping for genome-wide analysis of loss-offunction mutations. Am J Hum Genet. 2015:96:913-25. Available from: http://www.sciencedirect.com/science/article/pii/S0002929715001500. Cited 5 June 2015

44. Garber KB, Hyland KM, Dasgupta S. Participatory genomic testing as an educational experience. Trends Genet. 2016; Available from: http://www sciencedirect.com/science/article/pii/S0168952516300038. Accessed 15 Apr 2016.

45. Callier SL, Toma I, McCaffrey T, Harralson AF, O'Brien TJ. Engaging the next generation of healthcare professionals in genomics: planning for the future. Per Med. 2014;11:89-98. Available from: http://www.futuremedicine.com/ doi/10.2217/pme.13.99. Cited 22 Nov 2016

46. Gerhard GS, Paynton B, Popoff SN. Integrating cadaver exome sequencing into a first-year medical student curriculum. JAMA. 2016;315:555-6. Available from: http://jama.jamanetwork.com/article.aspx?articleid=2481601. Cited 25 Apr 2016

47. Zaaijer S, Erlich Y. Using mobile sequencers in an academic classroom. elife. 2016;5:e14258. Available from: http://elifesciences.org/content/5/e14258v1/ article-info. Cited 8 Apr 2016

48. Irwin M, Artin KH, Oxman MN. Screening for depression in the older adult: criterion validity of the 10-item Center for Epidemiological Studies Depression Scale (CES-D). Arch Intern Med. 159:1701-4. Available from: http://www.ncbi.nlm.nih.gov/pubmed/10448771. Cited 22 Apr 2016

\section{Submit your next manuscript to BioMed Central and we will help you at every step:}

- We accept pre-submission inquiries

- Our selector tool helps you to find the most relevant journal

- We provide round the clock customer support

- Convenient online submission

- Thorough peer review

- Inclusion in PubMed and all major indexing services

- Maximum visibility for your research

Submit your manuscript at www.biomedcentral.com/submit

) Biomed Central 